\title{
Resilience and mental health in individuals with spinal cord injury during the COVID-19 pandemic
}

\author{
Brian Mikolajczyk ${ }^{1}$, Christina Draganich (iD) ${ }^{2}$, Angela Philippus (iD) ${ }^{3}$, Richard Goldstein ${ }^{1}$, Erin Andrews ${ }^{4,5}$, Carrie Pilarski $^{6}$, Robert Wudlick ${ }^{1}$, \\ Leslie R. Morse ${ }^{1}$ and Kimberley R. Monden (iD ${ }^{1 \times}$
}

(c) The Author(s), under exclusive licence to International Spinal Cord Society 2021

STUDY DESIGN: Cross-sectional, observational study.

OBJECTIVES: To understand how resilience, access to personal care attendants (PCAs) and medical supplies, and concerns about medical rationing, finances, and social isolation are related to overall and mental health in individuals with spinal cord injury (SCI) in the context of the COVID-19 pandemic.

SETTING: Community dwelling adults $(N=187)$ with $\mathrm{SCl}$.

METHODS: Data were collected online between May 1, 2020 and August 31, 2020. Outcomes were overall and mental health, depression and anxiety symptoms, and quality of life (QoL). Predictors were resilience, access to PCAs and medical supplies, and concerns about medical rationing, finances, and social isolation.

RESULTS: Incomplete injury, concern about medical rationing, medical supply disruption, and social isolation predicted a greater perceived impact of the pandemic on overall heath. Younger age, decreased resilience, and concern about medical rationing and social isolation predicted greater perceived impact of the pandemic on mental health. Decreased resilience and concern about medical rationing and finances predicted increased anxiety symptoms. Incomplete injury, believing that medical rationing was occurring, decreased resilience, and concern about finances and social isolation predicted increased depressive symptoms. Decreased resilience and concern about finances, medical rationing, and social isolation predicted lower QoL.

CONCLUSIONS: The negative effects of the pandemic on the overall and mental health of individuals with $\mathrm{SCI}$ may be ameliorated by resilience. In future crises, it may be beneficial to screen individuals for resilience so that those with decreased resilience are offered the appropriate resources to enhance resilience and improve overall wellbeing.

Spinal Cord (2021) 59:1261-1267; https://doi.org/10.1038/s41393-021-00708-3

\section{INTRODUCTION}

The COVID-19 pandemic has negatively impacted the physical and psychological well-being of a large proportion of the global population [1]. Compounding the obvious fear of contracting SARS-CoV-2, measures intended to mitigate the spread of the virus, including physical distancing recommendations and shelterin-place orders, have had unfortunate mental health consequences such as increased rates of anxiety, depression, stress, and feelings of social isolation [2]. Exacerbating matters further, the economic downturn has resulted in a sharp rise in worldwide unemployment and financial insecurity, which is a major risk factor for mental health disorders including depression and suicide [3].

For the disabled community, the time during the COVID-19 pandemic has been fraught with unique challenges and disadvantages. Even in non-crisis times, individuals with disabilities have higher rates of depression and loneliness [4], as well as increased barriers to mobility, transportation, and healthcare services [5]. These individuals are thus particularly vulnerable to marginalization during a global viral pandemic that is not only acutely damaging the mental health status of the population overall, but also stressing healthcare delivery systems and resource capacity. Medical rationing, the allocation of scarce healthcare resources that may involve withholding potentially beneficial or even life-saving treatments from certain individuals, is more likely to occur in the environment of a pandemic that stretches healthcare infrastructure and employees to their limits with growing numbers of patients presenting as critically ill [6]. During this rationing of healthcare resources, there is concern that those with disabilities might be triaged away from life-saving care for a variety of reasons (e.g., higher-risk status, fewer life-years remaining, require more scarce healthcare services, and supplies) $[6,7]$. Additionally, many in the disabled community require regular appointments with rehabilitation specialists and personal care attendants (PCAs) and thus may require close contact with healthcare providers. While these regular healthcare appointments may increase the risk of viral transmission, they are often essential for the patient and the disruption of care due to physical

\footnotetext{
${ }^{1}$ Department of Rehabilitation Medicine, University of Minnesota Medical School, Minneapolis, MN, USA. ${ }^{2}$ Department of Physical Medicine and Rehabilitation, University of Colorado School of Medicine, Aurora, CO, USA. ${ }^{3}$ Research Department, Craig Hospital, Englewood, CO, USA. ${ }^{4}$ VA Texas Valley Coastal Bend Health Care System, Harlingen, TX, USA. ${ }^{5}$ The University of Texas at Austin Dell Medical School, Austin, TX, USA. ${ }^{6}$ Department of Physical Medicine and Rehabilitation, Division of Rehabilitation Psychology/ Neuropsychology, University of Michigan, Ann Arbor, MI, USA. ${ }^{{ }^{2}}$ email: kmonden@umn.edu
} 


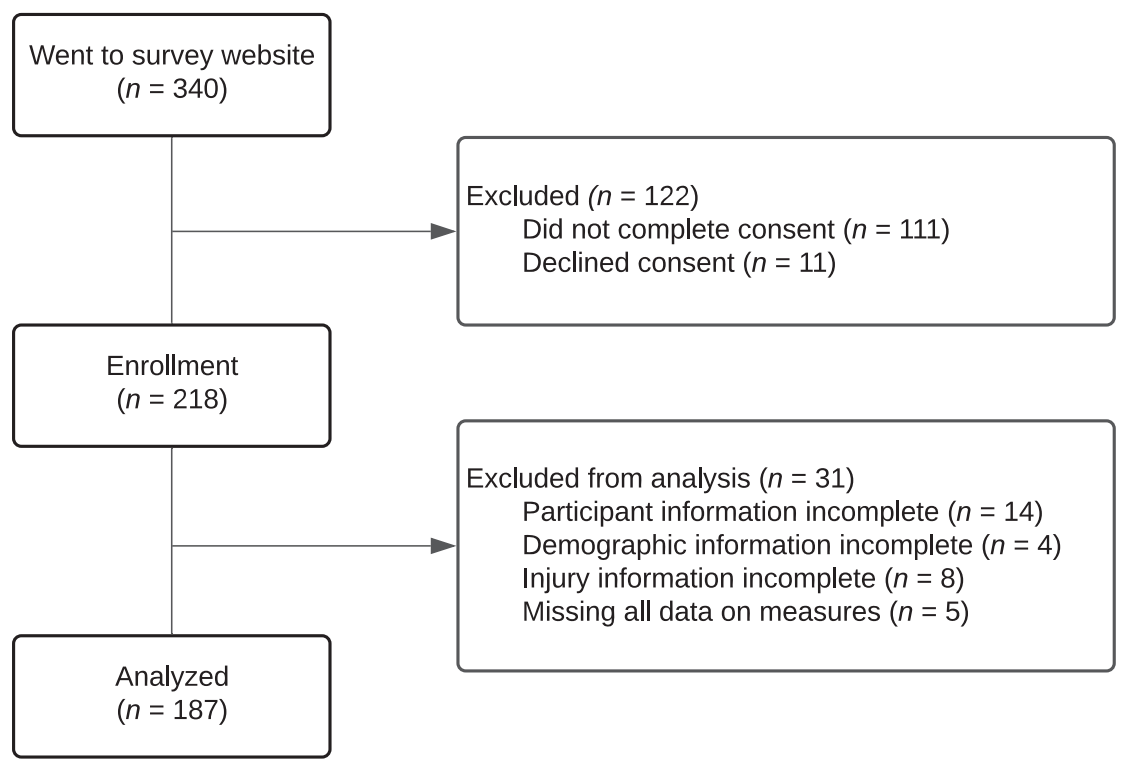

Fig. 1 Enrollment diagram for inclusion in the study.

distancing policies can have detrimental consequences. Further study is needed, but preliminary research suggests that those with physical disabilities, such as spinal cord injury (SCI), have decreased access to healthcare, decreased levels of resilience, and increased incidence of mental health disorders such as depression during the COVID-19 pandemic [8].

While it is possible, if not probable, that the overall and mental health of individuals with $\mathrm{SCl}$ during the pandemic is being negatively impacted by concerns regarding medical rationing, access to PCAs and medical supplies, financial stability, and social isolation, these relationships have not heretofore been rigorously and quantitatively studied in the literature. Additionally, while resilience has been well documented to boost overall and mental health outcomes in the $\mathrm{SCl}$ community $[9,10]$, this relationship has not been thoroughly studied during the current pandemic. Gaining an understanding of the current $\mathrm{SCl}$ community needs is a necessary first step for targeting interventions and care during the pandemic. The purpose of the present study is to understand how access to PCAs and medical supplies, resilience, and concerns about medical rationing, personal finances, and social isolation are related to overall and mental health in the context of the COVID19 pandemic. Given that our data were collected during the COVID-19 pandemic, which continues at the time of this publication, our findings are intended to be of ongoing relevance.

\section{METHODS}

This study reports observational, cross-sectional findings from a larger longitudinal study. Data were collected online using REDCap between May 1, 2020 and August 31, 2020. The University of Minnesota Institutional Review Board approved this study. We certify that all applicable institutional and governmental regulations concerning the ethical use of human volunteers were followed during the course of this research.

\section{Participants}

Participants were recruited internationally through distribution of recruitment materials to $\mathrm{SCl}$ stakeholder groups, including the North American Spinal Cord Injury Consortium, the Paralyzed Veterans of America, and the European Spinal Cord Injury Federation. Participants were also recruited through social media channels, including Twitter and Facebook. Participants included in the study had a diagnosis of SCl or disorder (SCl/D) through self-report, were 18 years or older, and were able to comprehend English. A total of 218 participants enrolled in the study; however, 31 participants were excluded from analysis (Fig. 1). Therefore, the total analytic sample consisted of 187 individuals.

\section{Variable definition}

Outcomes. The primary outcomes of interest were overall health, mental health, depression and anxiety symptoms, and quality of life (QoL). Participants were asked to rate how the COVID-19 pandemic has impacted their overall health on a scale from one (no impact) to four (major impact). Using the same scale, they were asked one question related to their overall mental health: How has the COVID-19 pandemic impacted your mental health? Symptoms of depression were assessed using the 8-item Patient Health Questionnaire (PHQ-8) [11]. Scores on the PHQ-8 range from 0 to 24 , where higher scores indicate higher severity of depression symptoms. The PHQ-8 is well-validated, reliable, and has been used extensively in SCI research [12-14]. Symptoms of anxiety were assessed using the 7-item Generalized Anxiety Disorder measure (GAD-7) [15]. Scores on the GAD-7 range from 0 to 27 , where higher scores indicate higher severity of anxiety symptoms. The GAD-7 demonstrates good reliability and validity [15]. QoL was measured using the International Spinal Cord Injury Quality of Life Basic Data Set (QoL BDS) [16]. The QoL BDS assesses three aspects of QoL: satisfaction with general QoL (overall well-being), satisfaction with physical health, and satisfaction with psychological health. Each factor is rated on a $0-10$ scale from 0 (completely dissatisfied) to 10 (completely satisfied). The QoL BDS has demonstrated good reliability and validity $[16,17]$.

Predictors. Our primary predictors of interest were resilience, concerns about medical rationing and discrimination, concerns about financial stability, concerns about access to PCAs and medical supplies, and concerns about social isolation. Resilience was assessed with the SCI-QoL Resilience Short Form, an 8-item measure that asks participants to rate how often they experience each item on a scale from 0 (never) to four (always) [9]. Higher scores on the SCI-QoL Resilience indicate higher levels of resilience. The SCl-QoL Resilience was developed specifically for use in the $\mathrm{SCl}$ population and demonstrates good psychometric properties [9]. Participants were asked three questions related to medical rationing and discrimination: (1) If you are hospitalized during the COVID-19 pandemic and need a ventilator, are you concerned that you will not get one due to your SCI? (yes/no); (2) In the past three months, do you believe medical discrimination in the form of medical rationing is currently taking place where you live? (yes/no); and (3) If you are now or in the future diagnosed with COVID-19, how fearful are you that you will not receive appropriate medical care (e.g., access to a ventilator) because of your disability status? (0 (not at all fearful) to 100 (very fearful)). The survey included two questions about financial concerns: (1) Right now, how concerned are you about personal finances due to the COVID-19 pandemic? ( 0 (not concerned at all) to 100 (very concerned)); and (2) How has the COVID-19 pandemic impacted you financially? (0 (no impact) to four (major impact)). Participants who indicated they required a PCA or nurse were asked to rate the impact of the pandemic on the care they receive in their home on a scale from one (no impact) to four (major impact). All participants were asked to rate the impact of the pandemic on their access to medical 
supplies on a scale from one (no impact) to four (major impact). Participants were asked two questions related to social isolation: (1) Right now, how bothered are you about being socially isolated due to the COVID-19 pandemic?; and (2) Thinking about the future, how concerned are you about continued social isolation due to the COVID-19 pandemic? Both questions were rated on a scale from 0 (not concerned at all) to 100 (very concerned).

The following demographic and injury characteristics were considered as potential predictors of the outcomes: age, education level, race, gender, employment status, level of injury, injury completeness, and injury etiology. Education was categorized as less than a high school diploma, high school diploma/GED, some college, college degree, and graduate/ professional degree. Race was categorized as White, Black, Asian, American Indian/Alaskan Native, and Native Hawaiian/other Pacific Islander. Gender was categorized as man, woman, or transgender/other related category. Employment status was categorized as not employed for pay, employed for pay, or disability/VA/worker's compensation. Level of injury was classified as tetraplegia or paraplegia, injury completeness as complete or incomplete, and injury etiology as traumatic or non-traumatic.

\section{Statistical analysis}

All statistical analyses were conducted using Stata (version 16) [18]. The outcomes of overall health and mental health were modeled using ordinal logistic regression. Depression, anxiety, and quality of life outcomes were modeled using linear regression. All candidate predictors were considered for each outcome modeled. Due to a large number of candidate predictors, modeling was done in stages with the candidate predictors grouped a priori, as follows: demographic information, injury-related characteristics, medical discrimination and rationing, and resilience.

Prior to modeling, a check for linearity was made for each continuous candidate predictor using locally weighted scatterplot smoothing (LOWESS) [19]. In checking for possible non-linear relationships, the depression and quality of life models showed a piecewise linear relationship with a knot or break at a score of 18 on the SCI-QoL Resilience, which has a score range of 0 to 32. Therefore, resilience was modeled with a piecewise linear spline with a knot at a score of 18 .

Due to the amount of missing data, multiple imputation [20] was used with 25 imputed data sets. The imputations were checked for issues. Finally, after a projected final model was produced it was checked for violations of assumptions, including the proportional odds assumption underlying the ordered logit model used for the outcomes of overall health and mental health. A $p$-value of 0.05 was used for statistical significance.

\section{RESULTS}

\section{Participant characteristics}

Demographic and injury characteristics are summarized in Table 1. The average age of the participants was $57(S D=14.5)$ years at the time of the survey. The majority of the sample identified as male $(73.8 \%)$, White $(92.6 \%)$, and resided in private residences $(94.1 \%)$ in the United States (86.6\%). The average time since injury was $20.4(S D=14.9)$ years, and the majority of the sample described their injuries as traumatic (86.6\%) and incomplete (67.5\%). A slim majority of the sample also reported having paraplegia $(51.7 \%)$. The sample did not include any participants who were dependent on mechanical ventilation.

\section{Predictors of the impact of the COVID-19 pandemic on overall health}

In the ordinal logistic regression model of overall health, completeness of injury, fear of not receiving medical care due to disability status, major impact on access to medical supplies, and being bothered by social isolation all significantly predicted a negative impact of the pandemic on overall health (Table 2). The resulting odds ratios indicate the probability of a subject indicating a higher response category of the outcome (from $1=$ no impact to $4=$ major impact) when the predictor variable increased by one unit. Individuals with complete injuries had a $53 \%$ lower likelihood of reporting that the pandemic had an impact on their overall health, compared to those with incomplete
Table 1. Summary of Participant Demographic and Injury Characteristics.

\begin{tabular}{|c|c|c|c|}
\hline Continuous Variables & $N$ & $M$ & $S D$ \\
\hline Age (years) & 187 & 57.0 & 14.5 \\
\hline Time post injury (years) & 171 & 20.4 & 14.9 \\
\hline Categorical Variables & $N$ & $\%$ & \\
\hline \multicolumn{4}{|l|}{ Gender } \\
\hline Man & 138 & 73.8 & \\
\hline Woman & 47 & 25.1 & \\
\hline Transgender or other related category & 2 & 1.1 & \\
\hline \multicolumn{4}{|l|}{ Race } \\
\hline White & 150 & 92.6 & \\
\hline Black & 8 & 4.9 & \\
\hline Other & 4 & 2.5 & \\
\hline [Missing] & [25] & - & \\
\hline \multicolumn{4}{|l|}{ Level of education } \\
\hline Less than high school & 2 & 1.4 & \\
\hline High school diploma/GED & 14 & 7.5 & \\
\hline Some college & 43 & 23.0 & \\
\hline College degree & 72 & 38.5 & \\
\hline Graduate/professional degree & 56 & 30.0 & \\
\hline \multicolumn{4}{|l|}{ Employment status } \\
\hline Not employed for pay & 89 & 48.1 & \\
\hline Employed for pay & 38 & 20.5 & \\
\hline Disability/VA/Worker's Comp & 58 & 31.4 & \\
\hline [Missing] & 2 & - & \\
\hline \multicolumn{4}{|l|}{ Country of residence } \\
\hline United States & 161 & 86.6 & \\
\hline United Kingdom & 14 & 7.5 & \\
\hline Canada & 3 & 1.6 & \\
\hline Netherlands & 3 & 1.6 & \\
\hline Germany & 2 & 1.1 & \\
\hline Ireland & 1 & 0.5 & \\
\hline Switzerland & 1 & 0.5 & \\
\hline Greece & 1 & 0.5 & \\
\hline [Missing] & [1] & - & \\
\hline \multicolumn{4}{|l|}{ Type of residence } \\
\hline Private residence & 176 & 94.1 & \\
\hline Hospital & 1 & 0.5 & \\
\hline Nursing home/skilled nursing facility & 3 & 1.6 & \\
\hline Assisted living facility & 6 & 3.2 & \\
\hline Other & 1 & 0.5 & \\
\hline \multicolumn{4}{|l|}{ Type of injury } \\
\hline Traumatic & 162 & 86.6 & \\
\hline Nontraumatic & 25 & 13.4 & \\
\hline \multicolumn{4}{|l|}{ Injury level } \\
\hline Paraplegia & 91 & 51.7 & \\
\hline Tetraplegia & 85 & 48.3 & \\
\hline [Missing] & [11] & - & \\
\hline \multicolumn{4}{|l|}{ Completeness of injury } \\
\hline Complete & 54 & 32.5 & \\
\hline Incomplete & 112 & 67.5 & \\
\hline [Missing] & [21] & - & \\
\hline \multicolumn{4}{|l|}{ Ventilator dependent } \\
\hline Yes & 0 & 0 & \\
\hline No & 100 & 100.0 & \\
\hline
\end{tabular}

$M$ mean, $S D$ standard deviation 
Table 2. Multivariable factors associated with impact of the COVID-19 pandemic on overall and mental health.

\begin{tabular}{|c|c|c|c|c|}
\hline Predictors by outcomes & OR & SE & $P$ & $95 \% \mathrm{Cl}$ \\
\hline \multicolumn{5}{|l|}{ Overall Health, $P<0.001$} \\
\hline Time since injury & 0.98 & 0.01 & 0.065 & $0.96,1.00$ \\
\hline \multicolumn{5}{|l|}{ Completeness of injury } \\
\hline \multicolumn{5}{|l|}{ Incomplete (reference) } \\
\hline Complete & 0.47 & 0.15 & 0.018 & $0.25,0.88$ \\
\hline $\begin{array}{l}\text { Fear of not receiving } \\
\text { medical care due to } \\
\text { disability status }\end{array}$ & 1.02 & 0.01 & 0.003 & $1.01,1.03$ \\
\hline \multicolumn{5}{|l|}{ Access to medical supplies } \\
\hline \multicolumn{5}{|l|}{ No impact (reference) } \\
\hline Minor impact & 1.79 & 0.60 & 0.085 & $0.92,3.45$ \\
\hline Moderate impact & 1.65 & 0.66 & 0.209 & $0.76,3.59$ \\
\hline Major impact & 11.29 & 8.92 & 0.002 & $2.40,53.07$ \\
\hline $\begin{array}{l}\text { Bothered by social } \\
\text { isolation }\end{array}$ & 1.01 & 0.01 & 0.004 & $1.00,1.02$ \\
\hline \multicolumn{5}{|l|}{ Mental Health, $P<0.001$} \\
\hline Age & 0.98 & 0.01 & 0.041 & $0.96,1.00$ \\
\hline $\begin{array}{l}\text { Fear of not receiving } \\
\text { medical care due to } \\
\text { disability status }\end{array}$ & 1.01 & 0.01 & 0.034 & $1.00,1.02$ \\
\hline $\begin{array}{l}\text { Bothered by social } \\
\text { isolation }\end{array}$ & 1.03 & 0.01 & $<0.001$ & $1.02,1.04$ \\
\hline Resilience (SCI QOL R) & 0.90 & 0.02 & $<0.001$ & $0.86,0.95$ \\
\hline
\end{tabular}

$O R$ odds radio, $\mathrm{Cl}$ confidence interval

injuries $(\mathrm{OR}=0.47 ; 95 \% \mathrm{Cl} 0.25,0.88)$. Participants who were more fearful of not receiving medical care due to their disability status were slightly more likely to report their overall health being negatively impacted by the pandemic $(\mathrm{OR}=1.02 ; 95 \% \mathrm{Cl} 1.01$, 1.03). Participants who reported a major impact on their access to medical supplies were over 10 times more likely to report that the pandemic impacted their overall health compared to subjects who reported no impact on access to medical supplies (OR $=11.29$; $95 \% \mathrm{Cl} 2.40,53.07)$. Participants who reported being bothered by social isolation were slightly more likely to report that the pandemic had an impact on their overall health than those who were not bothered by isolation $(\mathrm{OR}=1.01 ; 95 \% \mathrm{Cl} 1.00,1.02)$. Note that this factor was significant $(p=0.004)$ even though the confidence interval appears to contain one. The lower bound has been rounded down from 1.0045 .

Time since injury $(\mathrm{OR}=0.98 ; 95 \% \mathrm{Cl} 0.96,1.00)$ and minor or moderate impact on access to medical supplies $(\mathrm{OR}=1.79$ and $1.65 ; 95 \% \mathrm{Cl} 0.92,3.45$ and $0.76,3.59$, respectively) did not significantly predict impact of the pandemic on overall health.

\section{Predictors of the impact of the COVID-19 pandemic on mental health}

In a second ordinal logistic regression, we identified several factors associated with the perceived impact of the pandemic on mental health (Table 2). For each additional year of age, the odds of reporting a greater impact of the pandemic on overall health decreased by $2 \%(\mathrm{OR}=0.98 ; 95 \% \mathrm{Cl} 0.96,1.00)$. Participants who expressed fear of not receiving medical care due to their disability status $(\mathrm{OR}=1.01 ; 95 \% \mathrm{Cl} 1.00,1.02)$ and those who were more bothered by social isolation ( $\mathrm{OR}=1.03 ; 95 \% \mathrm{Cl} 1.02,1.04)$ were slightly more likely to report a greater impact of the pandemic on their mental health. Participants with higher $\mathrm{SCl}-\mathrm{QoL}$ resilience scores were $10 \%$ less likely to report that pandemic had negatively impacted their overall health $(\mathrm{OR}=0.90 ; 95 \% \mathrm{Cl} 0.86,0.95)$.
Table 3. Multivariable Factors Associated with Symptoms of Anxiety and Depression.

\begin{tabular}{|c|c|c|c|c|}
\hline Predictors by outcome & B & SE & $\boldsymbol{P}$ & $95 \% \mathrm{Cl}$ \\
\hline \multicolumn{5}{|c|}{ Anxiety Symptoms $(G A D-7), r^{2}=0.48, P<0.001$} \\
\hline $\begin{array}{l}\text { Fear of not receiving } \\
\text { medical care due to } \\
\text { disability status }\end{array}$ & 0.03 & 0.01 & 0.003 & $0.01,0.06$ \\
\hline $\begin{array}{l}\text { Concern about } \\
\text { personal finances }\end{array}$ & 0.05 & 0.10 & $<0.001$ & $0.03,0.07$ \\
\hline Resilience (SCI QOL R) & -0.37 & 0.05 & $<0.001$ & $-0.47,-0.28$ \\
\hline \multicolumn{5}{|c|}{ Depression symptoms $(P H Q-8), r^{2}=0.50, P<0.001$} \\
\hline \multicolumn{5}{|c|}{ Completeness of injury } \\
\hline \multicolumn{5}{|l|}{ Incomplete (reference) } \\
\hline Complete & -1.56 & 0.71 & 0.029 & $-2.96,-0.16$ \\
\hline \multicolumn{5}{|l|}{$\begin{array}{l}\text { Belief that medical } \\
\text { rationing is occurring }\end{array}$} \\
\hline \multicolumn{5}{|l|}{ No (reference) } \\
\hline Yes & 1.39 & 0.69 & 0.046 & $0.025,2.76$ \\
\hline $\begin{array}{l}\text { Concern about personal } \\
\text { finances }\end{array}$ & 0.03 & 0.11 & 0.018 & $0.005,0.049$ \\
\hline $\begin{array}{l}\text { Belief that medical } \\
\text { rationing is occurring }\end{array}$ & 0.03 & 0.12 & 0.010 & $0.007,0.05$ \\
\hline Resilience (SCI QOL R) & -0.43 & 0.05 & $<0.001$ & $-0.53,-0.33$ \\
\hline
\end{tabular}

Anxiety symptoms. In this multivariable linear regression model, concerns about personal finances $(B=0.05, p<0.001)$ and fear of not receiving medical care due to disability status $(B=0.03, p=$ 0.003 ) were associated with increased anxiety (Table 3 ). Greater resilience, in contrast, was associated with decreased anxiety $(B=$ $-0.37, p<0.001)$.

Depression symptoms. In this multivariable linear regression model, complete $\mathrm{SCl}(B=-1.56, p=0.029)$ and higher levels of resilience on the $\mathrm{SCl}-\mathrm{Q}$ oL Resilience scale $(B=-0.43, p<0.001)$ were associated with fewer depressive symptoms (Table 3 ). Conversely, a belief that medical rationing is occurring $(B=1.39$, $p=0.046)$, concern about personal finances $(B=0.03, p=0.018)$, and being more bothered by social isolation $(B=0.03, p=0.010)$ were associated with increased depressive symptoms.

\section{Quality of life}

Overall well-being. Participants with $\mathrm{SCl}$ who expressed concern about personal finances were more likely to report decreased overall well-being (Table $4, B=-0.02, p=0.002$ ). Conversely, those individuals who reported higher resilience (specifically, a score $\geq 18$ on the $\mathrm{SCl}-\mathrm{Q}$ oL Resilience scale) reported greater overall well-being $(B=0.26, p<0.001)$.

Physical health. Participants who reported fear of not receiving medical care due to their disability status were less satisfied with their physical health (Table $4, B=-0.01, p=0.028$ ). As with overall well-being, those individuals with a SCI-QoL Resilience score $\geq 18$ reported greater satisfaction with their physical health $(B=0.24, p<0.001)$.

Psychological health. Participants who reported concern about future social isolation were less satisfied with their psychological health (Table $4, B=-0.02, p=0.001$ ). As with overall well-being and physical health, those individuals with a SCl-QoL Resilience score $\geq 18$ reported greater satisfaction with their psychological health $(B=0.30, p<0.001)$. 
Table 4. Multivariable factors associated with quality of life.

\begin{tabular}{|c|c|c|c|c|}
\hline Predictors by outcome & B & SE & $\boldsymbol{P}$ & $95 \% \mathrm{Cl}$ \\
\hline \multicolumn{5}{|l|}{ Satisfaction with Overall Well-Being, $r^{2}=0.43, P<0.001$} \\
\hline Concern about personal finances & -0.02 & 0.005 & 0.002 & $-0.02,-0.01$ \\
\hline Resilience (SCI QOL R<18) & -0.06 & 0.13 & 0.637 & $-0.32,0.20$ \\
\hline Resilience (SCI QOL R > 18) & 0.26 & 0.03 & $<0.001$ & $0.20,0.31$ \\
\hline \multicolumn{5}{|l|}{ Satisfaction with Physical Health, $r^{2}=0.38, P<0.001$} \\
\hline Fear of not receiving medical care due to disability status & -0.01 & 0.01 & 0.028 & $-0.02,-0.001$ \\
\hline Resilience (SCI QOL R > 18) & 0.24 & 0.03 & $<0.001$ & $0.18,0.30$ \\
\hline \multicolumn{5}{|l|}{ Satisfaction with Psychological Health, $r^{2}=0.51, P<0.001$} \\
\hline Concern about future social isolation & -0.02 & 0.01 & 0.001 & $-0.03,-0.01$ \\
\hline Resilience (SCI QOL R < 18) & -0.06 & 0.13 & 0.654 & $-0.32,0.20$ \\
\hline Resilience ( $\mathrm{SCI} \mathrm{QOL} \mathrm{R} \geq 18$ ) & 0.30 & 0.03 & $<0.001$ & $0.24,0.35$ \\
\hline
\end{tabular}

$B$ unstandardized coefficient, $\mathrm{Cl}$ confidence interval

\section{DISCUSSION}

We examined how resilience, access to PCAs and medical supplies, and concerns about medical rationing, personal finances, and social isolation are related to overall and mental health in individuals with $\mathrm{SCl}$ in the context of the COVID-19 pandemic. We found that incomplete injury, concern about medical rationing, disrupted access to medical supplies, and being bothered by social isolation predicted a greater perceived impact of the pandemic on overall health. Of note, participants who reported that the pandemic had a major impact on their access to medical supplies were more than 10 times more likely to report that the pandemic had negatively impacted their overall health, however, the confidence interval was wide $(\mathrm{OR}=11.29 ; 95 \% \mathrm{Cl}$ $2.40,53.07)$. This is likely due to the small sample size and we expect that with a larger sample the confidence interval would narrow.

Younger age, concern about medical rationing, being bothered by social isolation, and decreased resilience predicted a greater perceived impact of the pandemic on mental health. Concern about medical rationing and personal finances, as well as decreased resilience, predicted increased anxiety symptoms. Incomplete injury, a belief that medical rationing was occurring, concern about personal finances, being bothered by social isolation, and decreased resilience predicted increased depressive symptoms. Predictors of lower QoL included concern about personal finances, medical rationing, future social isolation, and decreased resilience.

One of the most consistent results from this study is that, broadly speaking, increased resilience had significant positive effects on individuals with $\mathrm{SCl}$ during the COVID-19 pandemic. This includes positive mental health impacts, including lower anxiety and depression levels, but also greater overall, physical, and psychological well-being. These findings are consistent with previous research that has demonstrated a positive impact of resilience on overall and mental health, including lower rates of depression in individuals with $\mathrm{SCl}$ [10]. Our results resonate with this literature and suggest that resilience may be as important, if not more so, during times of crisis, in buffering the negative impact of a global pandemic. In future crisis situations, individuals with $\mathrm{SCl}$ that have decreased resilience, and are thus more at risk for poorer overall and mental health outcomes, should be identified early to allow for appropriate intervention. Specifically, our results show that a score of 18 or greater on the SCl QoL Resilience measure is a potential therapeutic target or clinically relevant threshold for participants to experience the protective effect of resilience. Research has shown that cognitive-behavioral therapy (CBT) addressing mental health among individuals with $\mathrm{SCl}$ is effective [21] and preliminary research utilizing virtually based CBT for overall well-being was a feasible approach for individuals with $\mathrm{SCl}$ [22].

As the $\mathrm{SCl}$ community generally requires a greater amount of healthcare services and medical supplies than the overall population, they are likely to be disproportionately impacted by any medical rationing during a pandemic. Disability rights advocates, medical ethicists, and health care leaders have previously raised concerns about the potential for discriminatory and ableist health care rationing policies during the COVID-19 pandemic that could adversely impact the quality of life for individuals with disabilities, including those with SCI $[6,7]$. Our results indicate that concerns about medical rationing have had a detrimental impact on health outcomes in the $\mathrm{SCl}$ community during the pandemic. Specifically, individuals with $\mathrm{SCl}$ who had concerns about accessing medical supplies due to their disability status routinely reported worsened health outcomes, including poorer overall health, poorer mental health, increased anxiety symptoms, and poorer physical health. Similarly, the belief that disability-based discrimination and rationing of medical supplies was occurring was also associated with more depressive symptoms. These concerns in the $\mathrm{SCl}$ community regarding medical rationing are grounded in the realities of resource scarcity and historical precedent, but several options exist to possibly allay these fears and improve the overall and mental health of those with $\mathrm{SCl}$ during our current crisis. The $\mathrm{SCl}$ community should be made aware of their legal right not to be excluded from care on the basis of their disability [23]. Interdisciplinary healthcare teams should be encouraged to involve rehabilitation psychologists, who can advocate on the behalf of individuals with $\mathrm{SCl}$ to prevent unfair discrimination as it relates to access to medical supplies and healthcare. Bulk provisions of medical supplies should be made available to individuals with $\mathrm{SCl}$ to not only reduce the need to access public spaces, such as pharmacies or medical supply stores that would increase the risk of contracting SARS-CoV-2, but also to reduce the likelihood of any medical supply shortages for these individuals.

Other predictors were shown to be significantly correlated with health outcomes in individuals with $\mathrm{SCl}$ during the pandemic. Being concerned or bothered about social isolation correlated significantly with worsened health outcomes, including poorer overall health, poorer mental health, more depressive symptoms, and poorer psychological health. This is particularly troubling as the $\mathrm{SCl}$ community already faced increased social isolation and loneliness before the pandemic [24]. Given that previous research 
has elucidated the relationship between social isolation and worsened overall and mental health outcomes [25], the expected pandemic-related increase in social isolation should have been predicted to worsen health outcomes in this particularly vulnerable population, prompting timely mental health intervention. Additionally, rehabilitation psychologists are able to advocate for policies and funding that would assist community-based programs designed to connect individuals with disabilities and offer social activities to transition to virtual services in the context of a viral pandemic. Being concerned about personal finances were also linked to poorer health outcomes such as worsened anxiety, more depressive symptoms, and poorer overall well-being, whereas older age was found to be linked with better mental health outcomes during the pandemic. The economic recession resulting from the pandemic has created unemployment and personal financial crisis for many, but especially those with disabilities such as $\mathrm{SCl}$, as unemployment rates for the $\mathrm{SCl}$ community are historically as high as 10-fold greater than the overall population [26]. Also disproportionately impacted are younger individuals whose career and financial standing is typically less established than older individuals [27]. Further compounding this challenging time for young adults with $\mathrm{SCl}$ is the fact that, in general, younger individuals (18-29 years of age) already experience the highest rates of depression of any age bracket (21.0\%) [28]. Our results showing a relationship between increased concern about personal finances and poorer health outcomes are congruent with the documented evidence that vocational outcomes and financial security impact quality of life [3]. Given these results and the physical distancing limitations, rehabilitation psychologists should leverage telemedicine platforms to either initiate or continue mental health care of individuals with $\mathrm{SCl}$, particularly younger individuals and those at increased risk of social isolation and unemployment or financial hardship. Finally, complete $\mathrm{SCl}$, as compared to incomplete $\mathrm{SCl}$, was interestingly associated with better overall health and fewer depressive symptoms. Although it is understandable to predict worse health outcomes in those with complete $\mathrm{SCl}$, the literature pertaining to the impact of $\mathrm{SCl}$ completeness on depressive symptoms is mixed. Studies show a range of results, including increased, equivalent, and decreased severity of depression symptoms among individuals with complete $\mathrm{SCl}$ compared to incomplete SCI $[29,30]$. These mixed findings suggest that further research is necessary to elucidate the relationship, if any, between $\mathrm{SCl}$ completeness and health outcomes like depression.

Regarding limitations of our study, the participants were disproportionately White and male, as well as nearly exclusively residing in private residences in the United States. While a more proportionate study sample would be preferred, our regression results showed that other than advanced age being associated with better mental health outcomes, the other demographic predictor variables (e.g., race, gender, education, employment) were inconsequential in determining health outcomes, as were the level of injury and injury etiology. Additionally, the method of recruiting participants for our study, including using social media platforms, may introduce some sample selection bias, although the directionality of this bias is difficult to determine. There is also the possibility that the wording and dissemination methods of the survey may have resulted in unintentional exclusion or selection bias. Despite these limitations, our findings characterize many of the current needs and concerns among the $\mathrm{SCl}$ community during the pandemic as a starting point for advocacy and intervention. Additionally, given the continued pandemic, the need for ongoing research to characterize needs over time may be helpful.

\section{DATA AVAILABILITY}

Data are available from the lead author upon request.

\section{REFERENCES}

1. Vindegaard N, Benros ME COVID-19 pandemic and mental health consequences: Systematic review of the current evidence. Brain Behav Immun. 2020;e-pub ahead of print May 2020; https://doi.org/10.1016/j.bbi.2020.05.048.

2. Galea S, Merchant RM, Lurie N. The mental health consequences of COVID-19 and physical distancing: the need for prevention and early intervention. JAMA Intern Med 2020;180:817.

3. Kawohl W, Nordt C. COVID-19, unemployment, and suicide. Lancet Psychiatry. 2020;7:389-90.

4. Turner RJ, Beiser M. Major depression and depressive symptomatology among the physically disabled. Assessing the role of chronic stress. J Nerv Ment Dis 1990;178:343-50.

5. Stillman MD, Frost KL, Smalley C, Bertocci G, Williams S. Health care utilization and barriers experienced by individuals with spinal cord injury. Arch Phys Med Rehabil 2014;95:1114-26.

6. Andrews $\mathrm{EE}$, Ayers $\mathrm{KB}$, Brown KS, Dunn DS, Pilarski CR. No body is expendable: medical rationing and disability justice during the COVID-19 pandemic. Am Psychol. 2020 Jul 23;e-pub ahead of print 23 July 2020:https://doi.org/10.1037/ amp0000709.

7. Lund EM, Ayers KB. Raising awareness of disabled lives and health care rationing during the COVID-19 pandemic. Psychol Trauma Theory Res Pr Policy 2020;12: S210-1.

8. Felix E, Alvarado JV, Miranda-Cantellops N, Jackson S. Access limitations and level of psychological distress during the COVID-19 pandemic in a sample of individuals with spinal cord injury. Arch Phys Med Rehabil 2021;102:e5-e6.

9. Victorson D, Tulsky DS, Kisala PA, Kalpakjian CZ, Weiland B, Choi SW. Measuring resilience after spinal cord injury: development, validation and psychometric characteristics of the SCI-QOL Resilience item bank and short form. J Spinal Cord Med 2015;38:366-76.

10. Min J-A, Lee C-U, Hwang S-I, Shin J-I, Lee B-S, Han S-H, et al. The moderation of resilience on the negative effect of pain on depression and post-traumatic growth in individuals with spinal cord injury. Disabil Rehabil 2014;36:1196-202.

11. Kroenke K, Strine TW, Spitzer RL, Williams JB, Berry JT, Mokdad AH. The PHQ-8 as a measure of current depression in the general population. J Affect Disord 2009;114:163-73.

12. Wu Y, Levis B, Riehm KE, Saadat N, Levis AW, Azar M, et al. Equivalency of the diagnostic accuracy of the PHQ-8 and PHQ-9: a systematic review and individual participant data meta-analysis. Psychol Med. 2019;50:1-13.

13. Monden KR, Philippus A, Boals A, Draganich C, Morse LR, Ketchum JM, et al. Perceived injustice after spinal cord injury: evidence for a distinct psychological construct. Spinal Cord 2019;57:1031-9.

14. Lakhani A, Martin K, Gray L, Mallison J, Grimbeek P, Hollins I, et al. What is the impact of engaging with natural environments delivered via virtual reality on the psycho-emotional health of people with spinal cord injury receiving rehabilitation in hospital? findings from a pilot randomized controlled trial. Arch Phys Med Rehabil 2020;101:1532-40.

15. Spitzer RL, Kroenke K, Williams JBW, Löwe B. A brief measure for assessing generalized anxiety disorder: the GAD-7. Arch Intern Med 2006;166:1092.

16. Charlifue S, Post MW, Biering-Sørensen F, Catz A, Dijkers M, Geyh S, et al. International spinal cord injury quality of life basic data set. Spinal Cord 2012;50:672-5.

17. Post MWM, Adriaansen JJE, Charlifue S, Biering-Sørensen F, van Asbeck FWA. Good validity of the international spinal cord injury quality of life basic data set. Spinal Cord 2016;54:314-8.

18. StataCorp. 2019. Stata Statistical Software: Release 16. College Station, TX: StataCorp LLC

19. Cleveland WS. Robust locally weighted regression and smoothing scatterplots. J Am Stat Assoc 1979;74:829-36.

20. Abayomi K, Gelman A, Levy M. Diagnostics for multivariate imputations. J R Stat Soc Ser C Appl Stat 2008;57:273-91.

21. Craig A Short and long-term outcomes following cognitive behaviour therapy for people with SCl. In: Craig A, Tran Y, editors. Psychological dynamics associated with spinal cord injury rehabilitation: New directions and best evidence. New York: Nova Science Publishers; 2008.

22. Mehta S, Hadjistavropoulos H, Nugent M, Karin E, Titov N, Dear BF. Guided internet-delivered cognitive-behaviour therapy for persons with spinal cord injury: a feasibility trial. Spinal Cord 2020;58:544-52.

23. Mello MM, Persad G, White DB Respecting disability rights-toward improved crisis standards of care. N Engl J Med [Internet]. 2020;383. Available from: http:// www.nejm.org/doi/10.1056/NEJMp2011997

24. Robinson-Whelen S, Taylor HB, Feltz M, Whelen M. Loneliness among people with spinal cord injury: exploring the psychometric properties of the 3-item Loneliness Scale. Arch Phys Med Rehabil 2016;97:1728-34. 
25. Leigh-Hunt N, Bagguley D, Bash K, Turner V, Turnbull S, Valtorta N, et al. An overview of systematic reviews on the public health consequences of social isolation and loneliness. Public Health. 2017;152:157-71.

26. Ottomanelli L, Lind L. Review of critical factors related to employment after spinal cord injury: implications for research and vocational services. J Spinal Cord Med 2009;32:503-31.

27. "The Rising Age Gap in Economic well-being" Pew Research Center, Washington, D.C. (November 7, 2011) https://www.pewresearch.org/social-trends/2011/11/07/ chapter-1-wealth-gaps-by-age/.

28. Villarroel MA, Terlizzi EP Symptoms of depression among adults: United States, 2019. NCHS Data Brief, No. 379. Hyattsville, MD: National Center for Health Statistics.

29. Arango-Lasprilla JC, Ketchum JM, Starkweather A, Nicholls E, Wilk AR. Factors predicting depression among persons with spinal cord injury 1 to 5 years post injury. NeuroRehabilitation 2011;29:9-21.

30. Khazaeipour Z, Taheri-Otaghsara SM, Naghdi M. Depression following spinal cord injury: its relationship to demographic and socioeconomic indicators. Top Spinal Cord Inj Rehabil. 2015;21:149-55

\section{AUTHOR CONTRIBUTIONS}

KRM, LM, and RW were responsible for study design, oversight of data collection, extracting the data, interpreting results, and writing the manuscript. $B M, A P, C D, E A$ and $\mathrm{CP}$ contributed to the introduction, results, and overall editing of the manuscript. RG was responsible for the statistical analyses.

\section{COMPETING INTERESTS}

The authors declare no competing interests.

\section{ETHICAL APPROVAL}

The University of Minnesota Institutional Review board approved this study. We certify that all applicable institutional and governmental regulations concerning the ethical use of human volunteers were followed during the course of this research.

\section{ADDITIONAL INFORMATION}

Correspondence and requests for materials should be addressed to Kimberley $\mathrm{R}$ Monden.

Reprints and permission information is available at http://www.nature.com/ reprints

Publisher's note Springer Nature remains neutral with regard to jurisdictional claims in published maps and institutional affiliations. 